\title{
Situating design as social creation and cultural cognition
}

\author{
Christopher A. Le Dantec* \\ GVU Center and School of Interactive Computing, College of Computing, Georgia Institute of \\ Technology, Atlanta, GA 30332, USA
}

(Received 2 June 2010; final version received 13 September 2010)

\begin{abstract}
Video and transcripts of two architectural design meetings are presented in an analysis of a specific design process. The focus of the analysis presented here is the social and cultural aspects of cognition in design. The argument begins with a discussion of the parallels in design studies and cognitive science as each has begun to consider the importance of environmental influences on how we design and how we think. By applying three situated frameworks to understand the situated nature of design meetings, the analysis shows that notions of social creation and cultural cognition are complementary and necessary for a holistic understanding of the collaborative design process.
\end{abstract}

Keywords: social design; environmental perspectives of cognition; collaborative design; empirical studies; architecture

\section{Introduction}

Over the past fifty years, cognitive and social science has begun to look at the situated nature of human cognition. These perspectives have ranged from conceptualisations of cognition that account for the interaction between people and artefact (Hutchins 1996), to the highly contingent and situated nature of cognition (Suchman 1987, Greeno 1998), to explanations of cognition deeply embedded in culture and socialisation (Wertsch 1988, Shore 1998, Tomasello 1999). Some of these perspectives, like distributed cognition and situated action, stem from a radical re-thinking of human cognition that argues 'the traditional internal symbol process view of cognitive science has mistakenly attributed the properties of a complex, cognitive system, comprising both the individual and the environment to the individual mind' (Nersessian 2006). Here, the cognitive system can be understood as culture, which includes the social, psychological and material textures of human existence that provide a structure within which we learn and express ourselves.

At the same time, studies in design research have begun to consider the social construction of design. Over a roughly similar time period, design researchers have moved away from the designer as an individual font of creativity (Lawson 1990, Rowe 1995), to designer as social member in a collaborative endeavour (Brereton et al. 1996, Cross and Cross 1996, Le Dantec and Do 2009). Brereton in particular pointed out the role of social negotiation in the design process and attributed how

\footnotetext{
*Email: ledantec@cc.gatech.edu 
well the design functions to the success with which the team was able to negotiate the collaborative design process (Brereton et al. 1996). This earlier finding has been echoed in more recent work as well (Strickfaden et al. 2006, Kleinsmann et al. 2007). We can also see similar dynamics in Svihla's examination of how students learn collaborative design practices (see Svihla 2010). She points out that learning to design is, at least in part, a combination of learning about the process - i.e. applying expertise and experience - and learning about negotiating different perspectives on the constraints.

Despite these socially situated studies of design, cognitive science has been more thorough in accounting for what has been called an 'environmental perspective' of cognition (Nersessian 2006). Central to this view is that cognition is distributed through the environment, enculturated in practice, and situated in a particular social context. And while the theories that inform these different views are sometimes at odds with each other (Nardi 1996, Halverson 2002), they each foreground the importance of the environment in forming and enabling cognition. Design research has yet to develop an analogous environmental perspective of design; one that provides insight into different design processes across scales from individual designer, to the team of people collaborating on a design, to the culture of a particular design practice.

This paper is an attempt to cross-pollinate ideas of cultural cognition from cognitive science as useful for understanding the design process. In order to examine how and whether an environmental perspective of design has any basis in a realworld design context, video tape of architectural design meetings was used to analyse the distributed, enculturated and situated aspects of the design of a crematorium. The analysis presented here, first published in the proceedings of the seventh ACM conference on creativity and cognition (Le Dantec 2009), demonstrates how notions of cultural cognition are relevant to understanding design, and paired with analyses such as Shaw's (see Shaw 2010), establish a robust account of the cultural, practised and cognitive processes embodied in design.

\subsection{Social creation in design}

Earlier work in design research focused on the individual production of design (Lawson 1990, Rowe 1995). While these explanations of design provided some account of interaction with the social world, such interactions were largely viewed as forming constraints on the internal work of the designer (Lawson 1990). In these early works, design researchers were still dealing with romantic ideals of the designer and they did not take into account the rich social interactions that occur throughout the design process.

Several different researchers have since sought to bring in a broader understanding of the social world in which design is situated. In parallel work, Brereton et al., Cross and Cross, and Radcliffe focused on the role team dynamics played during the design of a bike rack (Brereton et al. 1996, Cross and Cross 1996, Radcliffe 1996). Their work marked some of the first efforts in design research to advance the consideration of social context in the design process.

The relationship design has to creativity represents another front in moving the understanding of design away from the individual actor toward one that is socially situated. Here again, the traditional view of creativity has lent itself to the presumption of the creative individual (Koestler 1964, Boden 1994, Gabora 2002); however, as others have pointed out, such a view of creativity undermines our ability 
accurately to assess the importance of the social setting as enabling and enhancing creativity (Warr and O'Neill 2005, Greenberg 2007).

By recognising the potency of the creative group, it is also necessary to recognise the need for varied points of view within the group. Importantly, the move toward considering the social setting of design must also consider collaboration that includes non-designers. As an example of how the social situation informs the design process, McDonnell analysed the social roles that designer and client don during collaboration and showed that they are only partly informed a priori (McDonnell 2009). She found that, throughout a collaborative design meeting, roles are renegotiated as part of the dynamic exchange in expertise. Her findings are consistent with Jones, who studied how artists and technologists collaborated to create new forms of expression, identifying the cultural exchange of domain expertise as a critical component of design (Jones 2005).

Using the notion of cultural exchange from Jones, it is reasonable to consider the collaboration between designer and client to be a variant of the collaboration between individuals with different domains of expertise. While some have endeavoured to model this cultural exchange (Gero 2002), more recent work has examined in more depth the different aspects of social creation in design. Le Dantec and Do revealed how value transfer occurs during design meetings (Le Dantec and Do 2009). They claimed that the introduction of values into the design discourse is an important component in the development of a shared understanding of the design space, and represents a key component in enabling the designer and client to asses the design. In a related study, Luck examined how idea production, ownership and conflict resolution are handled within a collaborative design meeting (Luck 2009). By analysing the spoken interactions, she was able to identify how participants in a design meeting recognise different non-tangible attributes of the design that might be beyond their expertise. By focusing on how designers engage with their clients, these researchers have been able to call attention to social design processes that are more difficult to identify when everyone in the room is an expert. This understanding in turn deepens the understanding of design as an intensely social practice and not simply a synthesis of training and creativity.

\subsection{Cultural cognition in design}

Cultural cognition, as the term is used here, refers to both the role of the environment and of the social practices - professional or otherwise - that support cognition. Hutchins's work provides the basis for understanding an environmentally informed notion of cognition (Hutchins 1995, 1996). His development of distributed cognition places an emphasis on understanding cognition as a coherent system of people, environment and supporting artefacts.

In his early work, Hutchins considered the bridge of a ship and the cockpit of an airplane, both systems that were highly procedural and which could be mapped to computation in a straightforward manner (Hutchins 1995, 1996). While the procedural nature of ships' bridges and airplanes' cockpits are demonstrative examples of distributed cognition, the framework can be instructive in domains ranging from the use of functional magnetic resonance imaging to the practices of biomedical laboratories (Nersessian et al. 2003a, Alač and Hutchins 2004).

However, while distributed cognition accounts for the use of media in the environment as part of the cognitive system, it does not account for the evolution of 
how those media are used over time. Understanding the evolution of tools and social practices falls under the rubric of cultural cognition (Nersessian et al. 2003a). While Nersessian holds with the general notions put forward by Hutchins, e.g. she considers 'cognitive artefacts as material media possessing the properties of generating, manipulating, or propagating representations' (Nersessian 2006), she demonstrates that these media are not fixed tools but are constantly being repurposed or re-designed in ad hoc response to problems that arise in their context of use.

Like the laboratory settings of Nersessian's work, collaborative design requires a level of fluidity in how cognitive artefacts are explained within the system (McDonnell 2009). The need for fluid reconfiguration comes in part because of the specialisation that comes with design training. Specialisation in turn requires that groups of designers with complementary skills work together, making collaboration necessary since no one person can know everything about the design. This situation leads to a state Fischer calls the symmetry of ignorance (Fischer 1999): with specialised knowledge of how to solve a particular design problem distributed amongst designers and users, it becomes necessary to use external objects to express knowledge, build models, and come to a shared understanding. Yet this shared understanding and the cognitive tools and media that are employed to reach it are fluid and reconfigurable around the specific knowledge and practice represented within the context of collaborative design.

The social creation that occurs within design and the cultural and distributed qualities of design reasoning suggest that an environmental perspective of design should be able to weave these different elements together into a coherent view of collaborative design.

\section{Methodology}

While Hutchins's and Nersessian's contextual investigations discussed above were ethnographic in nature (Hutchins 1995, 1996, Nersessian et al. 2003a,b, Nersessian 2006), the analysis presented here uses data from a study of two architectural meetings and builds upon an earlier analysis of these meetings that focused on the role values play in the design discourse (Le Dantec and Do 2009). Both design meetings were video recorded from several angles, providing wide views of wholegroup dynamics that enabled analysis of gesture and body language, as well as a topdown view of the table that permitted the observation of drawings, sketches and tools that were used during the meeting. Transcripts of the meetings were coded using a grounded approach to qualitative analysis: codes were iteratively refined based on the conversational interaction between the members of the design meeting. Meeting data were then coded by a single researcher through four repeat processes that analysed the data from scratch. Each iteration occurred after spending several weeks away from the data and resulted in an acceptable degree of test-retest. The transcript data were triangulated with a basic analysis of gesture and sketching evident in the meeting video. The fidelity of the video limited the granularity of gesture and sketch analysis to simple indications that either had occurred - this limitation, however, did not affect our analysis of the negotiation of shared conceptual frameworks as participants discussed different aspects of the design.

While the recording equipment was visible to the meeting participants, every effort was made to be unobtrusive when collecting the data. A researcher was present 
during the design meetings, but did not participate in the design discourse and only interacted with the meeting participants a few times at the beginning of the meeting during equipment setup, and again toward the end of the meeting as the interaction became more casual. The meetings took place at the building site and, aside from the presence of an observer and equipment, represent normal interactions that occur between architect and client.

The two meetings took place seven months apart and represent mid- and latedesign milestones in the design of a crematorium. The first meeting was between the head architect, Adam, and the two clients, Anna and Charles. ${ }^{1}$ The stated goal of the first meeting was to familiarise Anna and Charles with the details in the design Adam had completed. To that end, Adam presented a number of drawings of the building design to familiarise the clients with how the design would accommodate the requirements of the project.

The second meeting was primarily a review of changes discussed during the first recorded meeting and a chance for final modifications to be made prior to the project moving forward into planning. A number of architectural drawings were again presented along with new 3-D renderings of the building and site plan. A second architect, Tony, was present at the meeting, along with a project manager from the architectural firm, Sally.

Throughout the presentation of the meeting analysis, references to the first and second meetings are presented as A1 and A2, respectively.

\section{Environmental perspective of design}

By analysing design with an environmental perspective, we can see how several different frameworks can be woven together to illuminate the complex nature of design. The key to looking at design in this framing is to acknowledge that design is not something that is done in the abstract, but rather an activity that is necessarily connected to its real-world expression. The context of the design, both in terms of how and for whom, cannot be intelligibly stripped away when studying how design happens, how designers think, and how stakeholders collaborate around the design. Each of the following sections include examples from the transcripts that demonstrate how the distributed, enculturated and situated aspects of design are made manifest in a design meeting.

\subsection{Distributed cognition in design}

In both meetings, but especially in A1, building a shared representation of the crematorium design was a priority. Without a shared understanding, neither Adam nor Anna nor Charles could begin to assess if the design would work in the real world. By the time A1 was recorded, much of the initial and more tenuous planning had been completed and Adam arrived at the meeting with a complete, but not final, set of plans. It was around these plans that the meeting took place. The site plan that Adam brought became the main focus of the meeting and acted as a repository for design modifications (see Figure 1). It was the medium used as long-term memory for the design and served as a shared artefact that each of the people in the meeting could access as they discussed the progression of the design.

The setup of of the meeting informed how cognition was distributed around the room and amongst the members of the group. As noted above, the site plans were in 


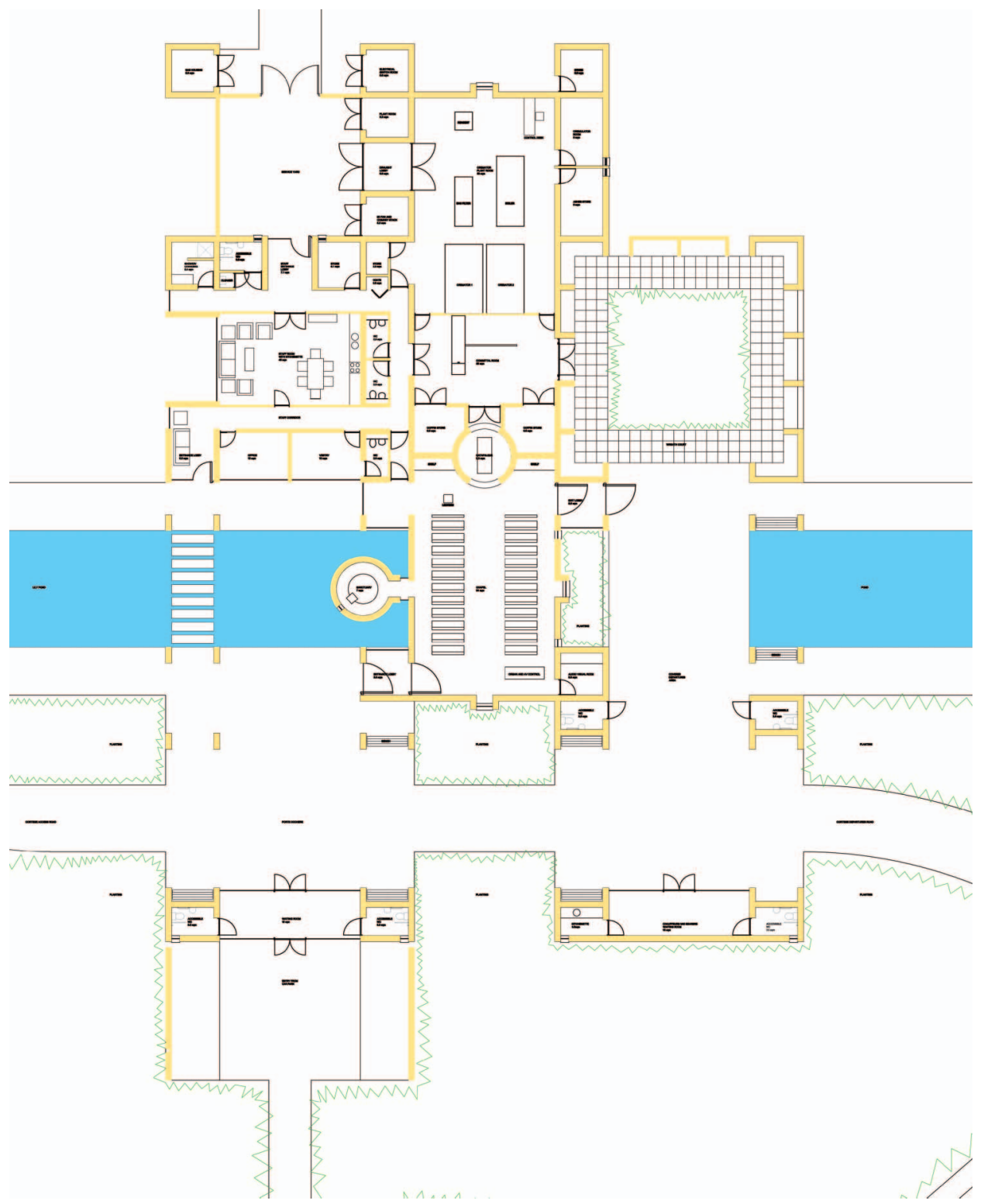

Figure 1. Crematorium site plan.

the centre where everyone had access. Additional tools for calculating scales, drawing modifications, taking notes, and providing external reference were also available, though not to every person at the meeting. For example, neither Anna nor Charles had access to modifying the site plan. They could gesture and point but they were never in a position to update the shared representation themselves. This point is interesting because it shows that while everyone could access the site plan as a form of shared representation, only Adam, as the architect, 'owned' the plan and was allowed to make changes to it. 
Throughout the design meeting, as different ideas or changes were suggested, Adam sketched the changes onto the site plan. Adam's sketches took place on tracing paper placed over the plan, a practice that enabled experimenting with several changes without actually scaring the plan and making the current state unreadable. By making modifications to external media such as the drawing, Adam updated the shared representation that everyone in the room had access too. The act of sketching played an important role in the design meeting and is consistent with previous work on sketching and design (Goldschmidt 1991, Arnheim 1995); however, beyond sketching, gesturing and pointing also played important roles in how the different members of the group accessed the shared representations and made 'calculations' about how the design should develop.

The use of gesture in conjunction with sketching enabled meeting participants to explain and interpret details depicted on the site plan as well as enact hypothetical modifications to the plan. Gestures provided a mechanism to indicate activity, scale, relationships of different building features, and direction or angle of view. Throughout the design meetings, gesturing was the main vehicle for inscribing meaning and solving problems around the design. Despite the impermanent nature of gesturing, it was used repeatedly and effectively to communicate complex concepts without requiring the specialised training associated with sketching. The effectiveness of gesture and the way it was shared between all members of the group exemplified both how multiple members with multiple specialisations contributed to the distributed system, and how design is an 'activity of the mind ... grounded in mechanisms that evolved for interaction with the environment' (Wilson 2002).

Over the course of the first design meeting, Adam's and Anna's use of gesture converged as they developed their understanding of the design space. For example, in Table 1 Adam explains how the funeral cars would arrive, where the hearses

Table 1. Meeting A1. Gesture and sketching.

Adam that wasn't the idea I was anticipating that the hearses would be parked here [sketches]

Anna we're there OK that's fine yeah

Adam exactly as they are at the moment that the coffin would be drawn out here and they would simply [points] walk it in I wasn't thinking that they'd try and park

Anna no that's OK

Adam in there

Anna yes well that's what they're wondering how that would work then so we'd work I wasn't quite aware

Adam we'd work it exactly the same way as the present system I mean maybe this should be made more obvious by perhaps a different colour in the paving or something [sketches] I mean what I'm trying to say here is that that's the vehicular line [sketches]

Anna yes

Adam and that these areas [points] are for people to mill about in and you've got a place for people to stand

Anna yes they will probably want to know how [points] how ... how far that is from the because they're going to be possibly carry the coffins in and most of the men are sort of in their seventies and eighties [laughs] carrying the coffin 
would park, and how coffins would be off-loaded and taken into the building for the service. There were a number of activities being explained, and in order to understand how each activity related to the other it was necessary to make transient changes, by way of gesture and sketching, to the site plan.

Gestures were also used when talking about features of the design that could not be communicated by the flat site plan. In the analysis of video from A1, Adam used large, sweeping gestures to describe the shape and placement of small windows in the crematorium's antechapel (see Figure 2). The gestures, in conjunction with details from the transcripts, indicated direct representations of shape and size but also had a metaphorical quality of how the space would engender calm and support the building's purpose as a place of mourning (see Table 2). In this case, the use of gestures to express both physical properties and metaphoric qualities is consistent with the findings of Casasanto and Lozano in their investigation of the role gesture plays in activating abstract concepts (Casasanto and Lozano 2006).

Through the course of sketching out changes, Adam used an architect's scale, which he kept adjacent to the drawing. An architect's scale looks much like a threesided ruler and easily enables translation between real-life measurements and the most common scaling factors used in architectural plans. Being able to translate quickly between the drawing and real-life measurements was necessary for Anna as she attempted to assess the fitness of the design. In Table 3, Adam explained a cross section drawing for the building and used the scale to draw in a small figure for Anna. Adam modified the external medium of the drawing to aid Anna's

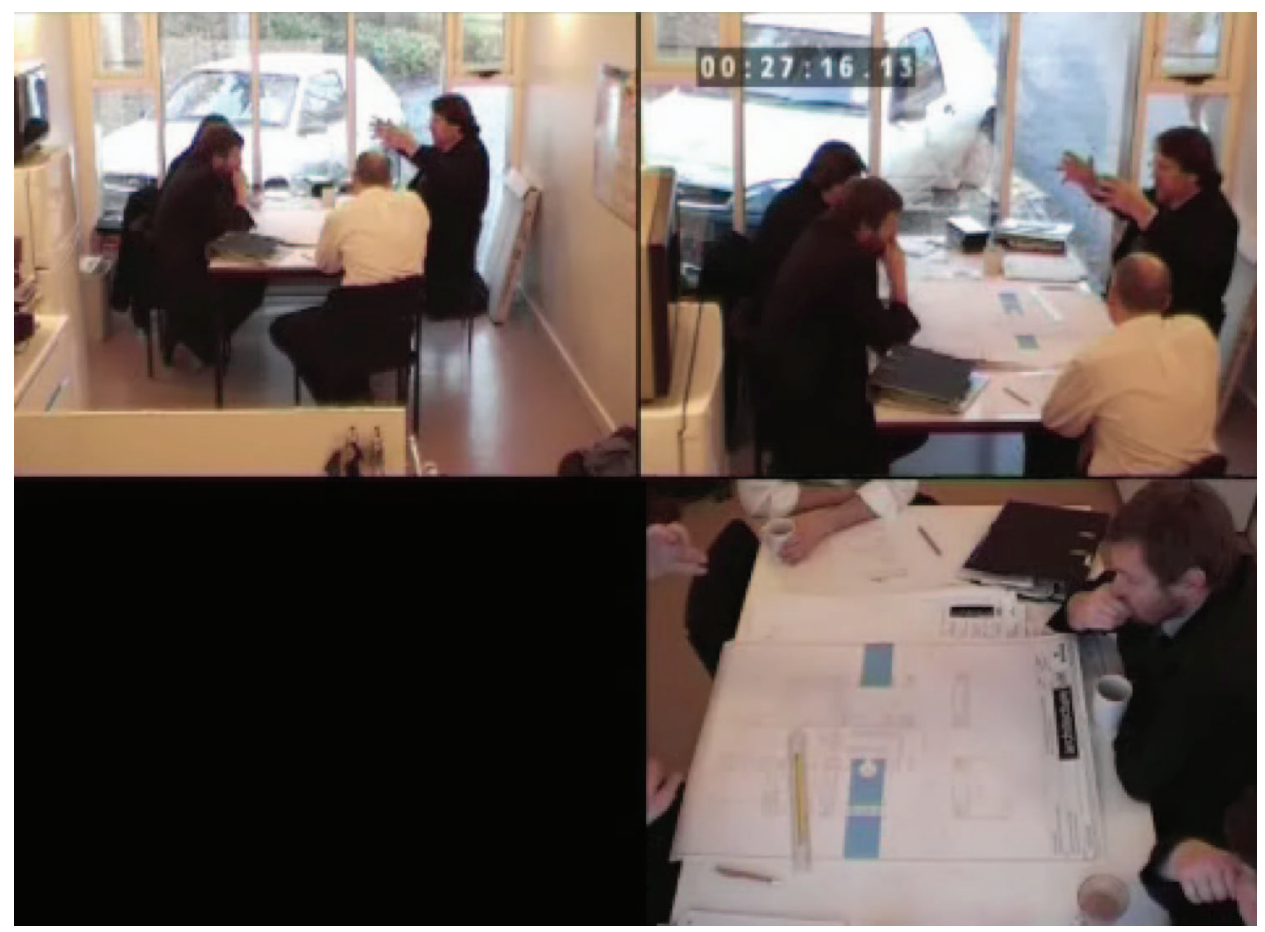

Figure 2. Adam - top right in top two frames, hands visible left side of bottom frame gesturing to indicate building features. 
Table 2. Meeting A1. The use of stained glass.

\begin{tabular}{ll}
\hline Anna & I'm thinking of Coventry Cathedral with the \\
Adam & oh yeah I know what you mean I've shown a very tall narrow slitty \\
& window which faces directly South if my orientation is correct or is it \\
& West? \\
Anna & little bit that's North [gestures] that would be North up this way ... \\
Adam & it faces directly \\
Anna & $\begin{array}{l}\text { South-west ... } \\
\text { Adam }\end{array}$ \\
& $\begin{array}{l}\text { it faces directly West to get the setting sun in it that was the original } \\
\text { idea I wanted to give you a small view of the pond as you came in and } \\
\text { you get a small view through it of the pond but if it's stained glass it'll } \\
\text { be a much more intimate space again top lit so you get sun and feeling } \\
\text { of any cloud movement overhead but essentially it's a very private } \\
\text { sanctuary that's why it'll be the sanctuary on the plan }\end{array}$ \\
\end{tabular}

Table 3. Meeting A2. Use of architect's scale.

\begin{tabular}{|c|c|}
\hline Adam & $\begin{array}{l}\text { this is what we call a section it's really a slice through the building } \\
\text { and this shows the cremator room here at the moment I think I've got } \\
\text { a scale here [shuffles papers] somewhere a scale of one mil to one } \\
\text { hundred yeah so it's ... from floor to the soffit there is four point nine } \\
\text { metres so it's quite tall ... I mean to get the scale right ... } \\
\text { the guy would be standing there like that }\end{array}$ \\
\hline Anna & OK [six seconds pause] OK \\
\hline Adam & so it's quite a high \\
\hline
\end{tabular}

understanding of how the plan related to real life by using the scale and drawing a representation of a person in the cross section of the building. These changes to the external media were not in response to negotiated changes to the design; rather, they enabled better translation of information across media to account for AP different specialisations.

The use of the architect's scale was one way the design was repurposed to enable different group members access to the details of the site plan. This repurposing of artefacts was very similar to the kinds of repurposing of equipment Nersessian observed in the laboratory (Nersessian 2006). Throughout the meetings Adam made small changes to the plans, usually through little sketches, notes, or by holding up items that would help establish scale. This repurposing was necessary as the types of problem being tackled in the design meeting were not fixed in nature; some issues might be about the size of a doorway, the height of a ceiling, or path the parking lot followed. Yet the site plan had to provide affordances for all of the meeting participants to manipulate any number of these different relationships. As a result, Adam would modify the plan when such affordances were missing or unclear.

In addition to being a repository for design changes, the site plan also acted as a model for testing how the design would accommodate the activities that take place at a crematorium. As above, Adam used gestures and pointing during the design meeting to indicate intended use, human traffic direction, and lines of sight. Table 1 demonstrates how sketching and gesturing were used in developing the design with an understanding of scale and activity. 
The range of activity that takes place around and on the different forms of external media show the complex nature of distributed design cognition. The discussion in the design meetings was freeform and the use of different parts of the site plan was not procedural as it was in Hutchins's work; yet, there are clear examples of different external media, of shared representations, and of channels of communication that are variously verbal, written and embodied. The way these influences are expressed in the design meetings can be further understood vis- à-vis Star's notion of boundary objects (Star 1989, Star and Griesemer 1989). In particular, the use of sketching and shared artefacts helps translate between the practices of the architect and those of the client while maintaining some privileged access to shared artefacts based on the roles of those in the design meeting. As the three individuals worked to refine the design and participate in its development, the external media of the site plan, the tools of calculation like the architect's scale, and the act of sketching and gesturing developed as a complex system of cognition.

\subsection{Enculturation in design}

While the process of group design can be described in terms of distributed cognition, the act of design also sits within a social and cultural heritage. Both cognition and design are formed and informed by various social and cultural forces, and to expose how these inform collaborative design we need to consider how those forces impact the design process. Talking about social and cultural forces can be difficult because these two terms are overburdened with connotation. Ghose pointed out the stickiness in considering culture and design by exposing two assumptions that get wrapped up in discussions of either: '[First,] that there exists something called design as ontological equipment ... [that] then could accommodate architectural, industrial, communications and fashion/garment design, woven together as it were by a common methodological thread. [Second,] that nation states have identifiable cultural, socioeconomic and aesthetic aspirations and predictable patterns of life, which despite all their variegated heterogeneities, exhibit at least a certain identifiable common cultural substance and provide the necessary tabula rasa on which modern design may be projected' (Ghose 1995). Ghose's sense of culture is tied to larger grained groups of people or states whereas the version considered here is slightly more malleable to include groups of professional practice in addition to the larger cultural domain in which those groups might sit (Wenger 1998, Strickfaden et al. 2006). In either case, the point remains - the assumption of design and culture as two monolithic concepts is problematic and obscures the nuanced influence each has on the other.

The notion of enculturated design presented here is derived from Shore's and Tomasello's work considering the cultural origins of human cognition (Shore 1998, Tomasello 1999). Put briefly, both argue in their various ways that the socialisation of the human mind is far more important to the development of cognition than genetic traits alone. By using their notion of cultural cognition, we can begin to see that the process of design is not just situated in a particular time and place, but also in a cultural context that informs the kinds of problems and solutions that are conceived through design. In this way we can see that the culture of design would exhibit traits of evolution; moreover, as several cultures mix together through the course of collaborative design, they influence each other in a process of co-evolution. In turn, the co-evolution of several cultures leads to notions of intertextuality and 
the mechanisms that inform how audience and designer communicate through designed objects (Barthes 1993, Frascara 1995, Krippendorff 1995, Tyler 1995).

One way to look at enculturation in design is by observing how different stakeholders express themselves. In the design meetings presented here, Anna and Charles represent a broader number of stakeholders not present at the meetings. Throughout the design discourse, both Anna and Charles take turns pointing out concerns that different stakeholders might have and explain the way they might see a particular requirement. In Table 4, Anna points out that funeral directors have a particular preference for moving coffins around during memorial services. The handborne coffin is the stated preference, despite issues of worker safety and the availability of a mobile catafalque that would aid in the process. By representing these wishes, despite their being against what she might consider good sense, Anna is creating a bridge to the culture of funeral directors and ensuring that culture is well represented in the design process.

Anna also works to defend the design against stakeholders who would detract from it. By being in the design process, she has been enculturated into a highly local practice of architectural design - between herself, Charles and Adam amongst the other actors not in view during the videos - in a way that external stakeholders were not. This enculturation gives her a sense of ownership in the design and, as she is meant to defend the needs and preferences of stakeholders in absentia, she is also assuming the role of defending the developing design from those same stakeholders. In Table 5, Anna explains how she defended the form of the new crematorium to the funeral directors, who did not universally appreciate the modernist shape of the building. Her participation in the design process has brought her in closer contact with design decisions, compelling her to defend a design she had a hand in. Her defence of the design is not just on the merits of the design, but also a point of cultural difference between herself as a participant in the design process and the funeral directors, who have not been direct participants.

The culture of the individual areas of expertise present at the design meeting is another aspect of enculturation; as mentioned above, access to modifying the site plan was strictly the purview of Adam. The reason for this is tied into the way in which the plans come to be used as a dynamic external representation for all of the participants in the design meeting. By preserving a particularly strong division of labour, the cognitive system of the design meeting can ensure that the external media

Table 4. Meeting A1. Funeral directors' preference.

Anna

they could use a bier yes they don't particularly like to they find it undignified some of them at the moment ...

Adam to use a trolley

Anna

a trolley yes I mean it's health and safety it's much easier for them to do that and the original concept of this chapel was that the bier the catafalque would actually come out and meet the hearse and it would be put on to the catafalque and then they would then wheel that in on there and so that was the original idea but that never really worked

Charles mainly because of the funeral directors

Anna funeral directors and the fact that they've always carried coffins in through churches and things like that there's still this concept of doing it of sort of shouldering them carrying them in 
do not get overwritten in ways that do harm to the representations held there. In essence, the enculturated practice of only allowing Adam to sketch ensures that a certain quality of sketch will be made, leading to better transfer and storage of information within the design meeting. Such practices have also been noted in other contexts where specific sketching practices meet with inexperienced team members (Johansson 2006).

While the analysis done here does not endeavour to pick apart the culture of architectural practice, there $i$ s culture and system of values that inform it. Adam's building design, having been based on the architectural fundamentals of Louis Kahn's Kimble Museum, tell us something about the kind of design culture Adam is a part of (i.e. high modernism). He brought Kahn's notions of servant and served space (see Table 6) into the design of the crematorium, and in so doing presented a radical departure from the design of contemporary crematoria the meeting participants discussed at the beginning of A1 - likening them to McDonald's and Tesco's, which are in turn part of a larger culture of contemporary British life.

This layer of different cultural influences creates a form of ratcheting consistent with the ideas put forward by Tomasello (1999). Advances made within the culture of architecture are applied to the design of the crematorium. These design choices also stand as a particular reaction to existing building design while incorporating knowledge about how best to support the funerary purpose of the building -

Table 5. Meeting A1. Dealing with negative feedback.

\begin{tabular}{|c|c|}
\hline Anna & $\begin{array}{l}\text { because I think what they can't quite see from the drawings obviously } \\
\text { the first drawings that we've got there is the the fact that some of them } \\
\text { have mentioned the feeling that they get from those sort of what they } \\
\text { think it is some of the comments that have been made about }\end{array}$ \\
\hline Adam & the aircraft hangar \\
\hline Anna & the aircraft hangar or a chicken hut or - \\
\hline Adam & [makes a sound with his lips] \\
\hline Anna & $\begin{array}{l}\text { I'm just pre-warning you what they might use as a comment so I don't } \\
\text { want to make you feel you know that's what they might mention but } \\
\text { they can't as I've said to them }\end{array}$ \\
\hline
\end{tabular}

Table 6. Meeting A1. Description of servant and served space, followed by application of the new concept.

Adam yes if I could go back to the architectural concept [pulls out drawing] on
that show you where I'm coming from I've done these concept diagrams
to try and explain how what holds the architecture together because the
building as I mentioned before is a combination of four strips of what we
call servant space which are low spaces and three strips of served space
which are the barrel vaulted spaces and you put those together and you
get this combination of ser - servant served servant served ...
again that will perhaps I'm trying to think of where that is in the that
1:18:00 what cover the that's the areas that you called the servant area
would be the end of that then wouldn't it


including the staff who care for the deceased, the family and friends who arrive to mourn, and the blend of function and spirituality that needs to be present to support both. Furthermore, by looking at the design process as one of enculturation, we can begin to understand how co-evolution occurs through the negotiation and convergence of several different cultures.

\subsection{Situatedness of design}

The physical setting for the design meeting is the most basic manifestation of the situated nature of the collaboration. The location, time of day, interruptions and social practices (like serving coffee) are all part of the physical situation in which the meeting is set. None of these characteristics may be unique to this design meeting, but they make up the backdrop against which the human interaction takes place. The physical setting informs the contingent actions and decisions that form the collaborative system creating the design, much in the way interactive systems can be viewed as embodied experiences (Bilda et al. 2007).

To that end, the design meeting centred around a table with Adam on one side and Anna and Charles across from him. On the table, Adam had a stack of architectural drawings that were used to guide discussions of the building's features. To Adam's right were a notebook, tracing paper and drawing implements such as pencils and rulers. The layout of equipment and positioning of people in the room informed the relationship between meeting participants for example, while both designer and client had equal access to the table and to the drawings that were placed on it, implements like pencils and tracing paper, as noted, were strictly reserved for Adam. Such aspects of physical and social situatedness of the design meeting are also irrevocably connected to the enculturated practice of design, and to the topology of the distributed cognitive system ascribed to the meeting location.

Suchman and Greeno offer slightly differing ways of understanding the situatedness of action. Greeno's version focuses more on the impact on learning within a situated practice and pulls in perspective on design from Simon and ideas of situated learning developed by Lave and Wenger (Lave and Wenger 1991, Simon 1996, Greeno 1998). Suchman's take emphasises the contingency of action within the situated context and represents a break from the assumption that action - and in this case design - can be adequately represented and understood via symbolic systems (Suchman 1987). Both of these views are instructive: on the one hand the situatedness of the design meeting certainly leads to learning via the kind of enculturation discussed above; on the other, the design decisions made are contingent in nature and not specifically amenable to the kind of procedural decomposition that can follow from symbol-system descriptions - in fact, design is about fostering the kinds of contingent responses to problems that result in creative emergence (Shaw 2010).

One way to understand the activities in the meetings is as a constant re-orienting of current design moves against the over-arching goal of completing a design of the crematorium. In order for the design to proceed, a certain type of work needs to be accomplished. Looking at how each party reveals their goals to each other, and responds in turn to those expressed goals, gives us an understanding of how the design process is neither a linear progression of ideas nor a set of systematic responses to known requirements. Rather, the activity in the design meeting is a 
collection of ad hoc design moves made in response to inquiries and clarifications from both designer and client.

In considering the interactions in the recorded design meetings, both meetings started with an explicit agenda. Despite this, the course of the meetings was fluid and ultimately followed a freeform process of engagement as the designer and client worked through the design and negotiated meaning around the site plan. This point draws directly from Situated Action in that the initial plan of actions was quickly abandoned once the work of design was underway (Suchman 1987). In the first meeting, it was not until over an hour into the meeting that Adam made a reference to his agenda, and that was to say that he lost it. Up to this point, the interactions were deep into the details about the building and the conversational flow was fluid as Adam, Anna and Charles were all more closely aligned along developing the details of the crematorium design.

By the second meeting, the agenda was used more prominently to steer the course of the dialogue. Adam had repeatedly to interrupt when the meeting veered from the agenda, bringing it back 'on track' to ensure all topics were covered. This kind of steering was particularly true when new avenues of contingent design were opened by Anna and Charles. In Table 7, Anna and Charles had become side-tracked by whether the number of cremators planned for the facility would be enough. Adam entertained their concerns for a little while but ultimately brought them back to the shared goals of the plan, pointing out that the number of cremators was decided previously and that making such a change at that time would imply a significant amount of re-work to the design.

The fluid nature of topic change demonstrates the situatedness of the design meeting; moreover, this type of fluid exchange enables creative responses to specific design problems. In several exchanges throughout the two design meetings, comparisons were made to other buildings known to all parties. The range of references included McDonald's and Tesco's as examples of what not to be, Le Corbusier's chapel at Ronchamp as an exemplar of spiritual design, and Coventry Cathedral's stained glass as achieving the kind of effect sought in the design of the main chapel. Because the flow of ideas was not tied to a regimented set of steps, all of the participants in the design meeting were able to add their own notions of what might work for a particular problem. Furthermore, these references were situated within the a culture of design and consumption that informed on-the-spot decisions

Table 7. Meeting A2. Discussion of the number of cremators.

\begin{tabular}{ll}
\hline Adam & well this is fairly fundamental - \\
Anna & yes \\
Adam & deciding the number of cremators \\
Anna & yes \\
Adam & because originally there were going to be no cremators \\
Anna & no that's right \\
Adam & and then we said there were two \\
Anna & yep \\
Adam & erm if you want us to look at three this might have a fundamental \\
& change on the whole width of this bay and so I think we need a clear \\
& direction from yourselves of how many cremators we are to look at \\
\hline
\end{tabular}


about how best to create or break reference to culturally understood elements in order to achieve a successful design.

In this sense, the meandering re-calibration of the design plan could be pointed to as a critical piece that enabled creativity in the meeting. The kind of conceptual distribution observed in these meetings was spread across all of the meeting participants, enabling each to present an idea, respond to other meeting member's ideas, and in turn generate innovation. The situatedness of the design meeting gave each meeting participant access to a greater distributed memory and a wider range of expertise on which to draw responses to the design problem.

Another aspect of the situated nature of the design meeting can be found by considering the situated learning that takes place when different domain experts work together (Lave and Wenger 1991, Greeno et al. 1996, Greeno 1998). With this in mind, we can understand the interactions that occur during the design meeting as situated learning. Not only is situated learning unavoidable, it is necessary for designer and client to be able to understand the nuances of each other's domain. Adam, as the trained architect, has access to very specific knowledge about building construction and how to shape the built space in a way that is appropriate for the crematorium. Likewise, Anna and Charles are expert in the requirements that need to be met by the design. As they worked together, they each needed to be able to understand the vocabulary and concepts of the other. This meant that while much of the design meeting was about the building, the details in the social interaction where about the concepts that were being used to construct the building and whether or not each side understood those concepts fully enough to judge how they fitted into the design. This negotiation of expertise can be viewed as a dual apprenticeship in that Anna and Charles became apprentice architects and Adam became an apprentice funeral director. As the two exchanged domain specific knowledge they each took on more responsibility in engaging with the other's domain. At an early point in the design, Adam learned what a catafalque was and as a result, was better able to understand what he was designing for. On the flip side, in Table 6, Anna and Charles began to understand the architectural principles that informed the building design and they worked that understanding into how they formulated requirements.

The overall picture that emerges here is that the situated nature of the design meeting plays an important role in informing how the design emerges as an artefact of negotiation and innovation. Learning on both the part of the client and the designer shapes the outcome and the creation of a small enculturated unit that shares specific knowledge, experience and goals. The contingency of the design process also points to the importance of distributing knowledge around the design setting so that the different participants can share information and knowledge across distributed media.

\section{Conclusion}

The cognitive, social and cultural work that goes into design becomes more clear after examining design meetings in situ. It is the process of negotiating a number of different cognitive resources and social mechanisms that enable collaborative design to take place. Identifying the design problem, building a potential solution and testing that solution against the activities meant to occur with and around the artefact all require access to cognitive features beyond the scope of the individual 
designer's mind. Building a shared representation that both designer and client can work from and manipulate is critical to moving a complex design forward.

The kinds of cultural and cognitive work highlighted here also become apparent in analyses of other contexts presented in this volume. As noted at the beginning of this paper, in Svihla's analysis of engineering students learning design the process is both social and technical as students move from theoretical explorations of the problem space toward developing a shared narrative that underpins design-based exploration of potential solutions (see Svihla 2010). Developing this shared narrative is an important part of establishing the common context - a kind of culture of design - around which the teams organise.

Turning to more cognitive based accounts of creativity in design, Shaw's analysis of how emergence in design activities arises through group interaction brings to the fore the role tools, context and diverse expertise play in generating new and novel design responses (see Shaw 2010). While Shaw's analysis is focused on weaving together two particular notions of emergence into a complementary whole, we cannot help but also see that the larger setting in which this emergence takes place bears similar hallmarks to the analysis of architectural design presented here, namely that there is an interplay between the enculturation of different design disciplines and visual representations of solutions that scaffold the group as a whole toward a final product.

In the architectural design case presented here, the facets of design that are situated, embodied and distributed are not always easily separated from each other: situated learning affects the adoption and convergence of a shared context and perspective; the way the meeting is physically situated informs how different types of cognitive artefacts will be used; the cultural practices of a particular design profession and the relationship with the client and other design team members affect the physical layout. That each of these pieces necessarily informs the other shows how deeply situated design is both through social creation and cultural cognition.

This paper began with a discussion of the similar arc design studies and cognitive science have gone through as frameworks in each domain have been created to consider the importance of our environment in how we design and how we think. As the the body of design research moves forward, it is imperative to continue to bring a coherent set of frameworks to bear on understanding how design is done. Through the analysis presented here, three such frameworks were used to understand a collaborative design meeting, showing the complementary traits of each framework in illuminating the rich and nuanced relationship the act of design has with the environment.

\section{Acknowledgements}

The author would like to thank Ellen Do for her support of this research and Nancy Nersessian for feedback on an earlier draft of this paper.

\section{Note}

1. The names of the meeting participants have been changed to preserve their privacy.

\section{References}

Alač, M. and Hutchins, E., 2004. I see what you are saying: action as cognition in FMRI brain mapping practice. Journal of Cognition and Culture, 4 (3-4), 663-700. 
Arnheim, R., 1995. Sketching and the psychology of design. In: V. Margolin and R. Buchanan, eds. The idea of design. Cambridge, MA: MIT Press, 70-74.

Barthes, R., 1993. Image-music-text. Waukegan, IL: Fontana Press.

Bilda, Z., Candy, L., and Edmonds, E., 2007. An embodied cognition framework for interactive experience. CoDesign, 3 (2), 123-137.

Boden, M., 1994. The dimensions of creativity. London, UK: MIT Press.

Brereton, M.F., et al., 1996. Collaboration in design teams: how social interaction shapes the product. In: Analyzing design activity. New York: Wiley, 319-341.

Casasanto, D. and Lozano, S., 2006. Metaphor in the mind and hands. In: Proceedings of 28th annual conference of the Cognitive Science Society, 26-29 July, Hillsdale, NJ: Lawrence Erlbaum, 142-147.

Cross, N. and Cross, A.C., 1996. Obervations of teamwork and social process in design. In: Analyzing design activity. New York: Wiley, 291-318.

Fischer, G., 1999. Symmetry of ignorance, social creativity, and meta-design. In: Proceedings of the 3rd conference on creativity \& cognition (C\&C'99), 11-13 October, 1999, Loughborough, UK. New York: ACM, 116-123.

Frascara, J., 1995. Graphic design: fine art or social science. In: V. Margolin and R. Buchanan, eds. The idea of design. Cambridge, MA: MIT Press, 44-55.

Gabora, L., 2002. Cognitive mechanisms underlying the creative process. In: Proceedings of the 4th conference on creativity \& cognition ( $\left.C \& C^{\prime} 02\right)$, 14-16 October 2002, Loughborough, UK. New York: ACM, 126-133.

Gero, J.S., 2002. Computational models of creative designing based on situated cognition. In: Proceedings of the 4th conference on creativity \& cognition (C\&C'02), 14-16 October 2002, Loughborough, UK. New York: ACM, 3-10.

Ghose, R., 1995. Design, development, culture, and cultural legacies in Asia. In: V. Margolin and R. Buchanan, eds. The idea of design. Cambridge, MA: MIT Press, 187-203.

Goldschmidt, G., 1991. The dialectics of sketching. Crativity Research Journal, 4 (2), 137-147.

Greenberg, S., 2007. Embedding a design studio course in a conventional computer science program. Technical report 2007-870-22, University of Calgary, Alberta, Canada.

Greeno, J.G., 1998. The situativity of knowing, learning, and research. American Psychologist, $1(53), 5-26$.

Greeno, J.G., Collins, A.M., and Resnick, L.B., 1996. Cognition and learning. Handbook of educational psychology. New York: Macmillan, 15-46.

Halverson, C.A., 2002. Activity theory and distributed cognition: or what does CSCW need to do with theories? Computer Supported Cooperative Work, 11, 243-267.

Hutchins, E., 1995. How a cockpit remembers its speeds. Congitive Science, 19, 265-288.

Hutchins, E., 1996. Cognition in the wild. Cambridge, MA: MIT Press.

Johansson, M., 2006. Collaborative sketching - co-authoring future scenarios with bits and pieces of ethnography. CoDesign, 2 (3), 179-189.

Jones, S., 2005. A cultural systems approach to collaboration in art \& technology. In: Proceedings of the 5th conference on creativity \& cognition (C\&C'05), 12-15 April 2005, London, UK. New York: ACM, 76-85.

Kleinsmann, M., Valkenburg, R., and Buijs, J., 2007. Why do(n't) actors in collaborative design understand each other? An empirical study towards a better understanding of collaborative design. CoDesign, 3 (1), 59-73.

Koestler, A., 1964. The act of creation. New York: Dell.

Krippendorff, K., 1995. On the essential contexts of artifacts or on the proposition that 'Design is making sense (of things)'. In: V. Margolin and R. Buchanan, eds. The idea of design. New York: MIT Press, 156-184.

Lave, J. and Wenger, E., 1991. Situated learning: legitimate peripheral participation (learning in doing: social, cognitive and computational perspectives). Burlington, MA: Cambridge University Press.

Lawson, B., 1990. How designers think - the design process demystified. 4th ed. New York: Architectural Press.

Le Dantec, C.A., 2009. Situated design: toward an understanding of design through social creation and cultural cognition. In: Proceeding of the seventh ACM conference on creativity and cognition (C\&C'09), 27-30 October 2009, Berkeley, CA. New York: ACM, 69-78. 
Le Dantec, C.A. and Do, E.Y., 2009. The mechanisms of value transfer in design meetings. Design Studies, 30 (2), 119-137.

Luck, R., 2009. 'Does this compromise your design?' Socially producing a design concept in talk-in-interaction. In: J. McDonnell and P. Lloyd, eds. About designing - analysing design meetings. Abingdon: Taylor \& Francis.

McDonnell, J., 2009. Feedback to the design: a study of the negotiation of contributions in design conversation between architects and building users. In: J. McDonnell and P. Lloyd, eds. About designing - analysing design meetings. Abingdon: Taylor \& Francis.

Nardi, B., 1996. Studying context: a comparison of activity theory, situated action models, and distributed cognition. In: B. Nardi, ed. Context and consciousness. Cambridge, MA: MIT Press.

Nersessian, N.J., 2006. The cognitive-cultural systems of the research laboratory. Organization Studies, 27 (1), 125-145.

Nersessian, N.J., et al., 2003a. Research laboratories as evolving distributed cognitive systems. In: Proceedings of the twenty-fifth annual conference of the Cognitive Science Society, 857862.

Nersessian, N.J., et al., 2003b. A mixed-method approach to studying distributed cognition in evolving environments. In: Proceedings of the international conference on learning sciences, 307-314.

Radcliffe, D.F., 1996. Concurrency of actions, ideas and knowledge displays within a design team. In: Analyzing design activity. New York: Wiley, 343-364.

Rowe, P.G., 1995. Design thinking. Cambridge, MA: MIT Press.

Shaw, B.G., 2010. A cognitive account of collective emergence in design. CoDesign International Journal of Cocreation in Design and the Arts, 6 (4), 225-243.

Shore, B., 1998. Culture in mind: cognition, culture, and the problem of meaning. New York: Oxford University Press.

Simon, H.A., 1996. The sciences of the artificial. 3rd ed. Cambridge, MA: MIT Press.

Star, S.L., 1989. The structure of ill-structured solutions: boundary objects and heterogeneous distributed problem solving. Distributed Artificial Intelligence, 2, 37-54.

Star, S.L. and Griesemer, J.R., 1989. Institutional ecology, 'translations' and boundary objects: amateurs and professionals in Berkeley's Museum of Vertebrate Zoology, 190739. Social Studies of Science, 19 (3), 387-420.

Strickfaden, M., et al., 2006. Untangling the culture medium of student designers. CoDesign, 2 (2), 97-107.

Suchman, L.A., 1987. In: Plans and situated actions: the problem of human-machine communication. Cambridge, UK: Cambridge University Press.

Svihla, V., 2010. Collaboration as a dimension of design innovation. CoDesign: International Journal of Cocreation in Design and the Arts, 6 (4), 245-262.

Tomasello, M., 1999. The cultural origins of human cognition. Cambridge, MA: Harvard University Press.

Tyler, A.C., 1995. Shaping belief: the role of audience in visual communication. In: V. Margolin and R. Buchanan, eds. The idea of design. Cambridge, MA: MIT Press, 104-112.

Warr, A. and O'Neill, E., 2005. Understanding design as a social creative process. In: Proceedings of the 5th conference on creativity \& cognition (C\&C'05), 12-15 April 2005, London, UK. New York: ACM, 118-127.

Wenger, E., 1998. Communities of practice: learning, meaning, and identity. New York: Cambridge University Press.

Wertsch, J.V., 1988. Vygotsky and the social formation of mind. Cambridge, MA: Harvard University Press.

Wilson, M., 2002. Six views of embodied cognition. Psychonomic Bulletin \& Review, 9 (4), 625636. 